\title{
UMA VISÃO SOBRE O DIREITO DO TRABALHO NO JAPÃO
}

\author{
Masato Ninomiya \\ Professor Doutor do Departamento de Direito Internacional \\ da Faculdade de Direito da Universidade de São Paulo \\ Aurea Christine Tanaka \\ Pós-graduanda em Direito Internacional na Faculdade de \\ Direito da Universidade de São Paulo
}

Resumo:

A história do Direito do Trabalho no Japão é recente, apesar de terem existido leis esparsas no início do século, principalmente depois que o Japão fez parte do Tratado de Versalhes, que criou a Organização Internacional do Trabalho. As leis que se encontram em vigor foram promulgadas depois da II Guerra Mundial, durante a ocupação das Forças Aliadas. O Ministério do Trabalho no Japão também foi criado neste período. Desde logo, percebem-se certas peculiaridades no Direito do Trabalho japonês, podendo apontar-se o sistema de contratação, os sindicatos nas empresas e a existência de instâncias administrativas (Comissões Trabalhistas) para solução de litígios. Embora a maior parte das questões acabem sendo resolvidas no âmbito das empresas, pode-se recorrer às Comissões Trabalhistas na falta de acordo e, em último caso, ao Poder Jucliciário. Se até agora o interesse em conhecer o Direito do Trabalho no Japão se resumia ao ponto de vista acadêmico, hoje, há um interesse prático ocasionado pela presença de um numeroso contingente de trabalhadores brasileiros naquele país.

Abstract:

The history of Japanese Labour Law is recent, in spite of having existed unconsolidated laws at the beginning of the century, mainly after Japan was part of the Versailles Treaty, which created the International Labour Organization. The laws which are in force were promulgated after the II World War, during the occupation of the Allied Powers. The Labour Ministry in Japan was also created in that period. At once, some peculiarities in the Japanese Labour Law are noted, being worth of mention the hiring system, the corporate unions and the existence of administrative jurisdictions (Labour Commissions) for the solution of disputes. Although most part of the conflicts are resolved inside the companies, it is possible to appeal to the Labour Commissions in case of disagreement and in last resort to the Judiciary Power. If, until now, the interest in knowing about the Labour Law in Japan 
was restricted to an academic point of view, nowadays, there is a practical interest caused by the presence of a numerous contingent of Brazilian workers in that country.

Unitermos: Direito do Trabalho; Japão.

\section{Introdução}

Assim como em vários países, o Direito do Trabalho no Japão surgiu como uma "natural reação contra as condições de trabalho" decorrentes da Revolução Industrial, "da formação do proletariado e da indiferença do Estado diante da questão social" como observa Amauri Mascaro Nascimento. '

$\mathrm{Na}$ falta de uma estrutura e legislação trabalhista, a incipiente industrialização do início do século no Japão mostrou a exploração da força de trabalho de mulheres e crianças, as péssimas condições de trabalho, jornadas longas, etc.

Nesta época, contudo, o direito de associação e a possibilidade de reivindicação por melhores condições de trabalho eram práticas severamente punidas e vistas como violações do contrato de trabalho, que era regido pelas leis civis e seus princípios contratuais: liberdade de contratar e igualdade entre as partes, dentre outros.

Entretanto, a relação trabalhista não pressupunha uma igualdade real, porquanto o empregador certamente tinha um poder que superava o do empregado, fazendo com que urgissem leis que restaurassem de certa forma esse equilíbrio de forças.

Dessa situação de necessária intervenção do Estado, adviria o que o prof. Amauri Nascimento coloca como concepção heterotutelar do trabalhador, no qual o Estado intervém de maneira a garantir a preservação de direitos básicos: "direito ao descanso, tripartindo-se na limitação da jornada diária de trabalho, no direito ao repouso semanal e na garantia de férias anuais, o direito ao justo salário, à proteção da vida, da saúde e da segurança física, à proibição de discriminações da mulher e do menor e outros valores. ${ }^{2}$ dentro de uma idéia protecionista de um

1. Nascimento, Amauri Mascaro. Curso de Direito do Trabalho, p. 82.

2. Nascimento, A. M., Op. cit., p. 83. 
Estado que é chamado a promover a defesa daquele que é economicamente mais fraco.

Ocorre, porém, que no Japão do pós-II Guerra Mundial, sob influência americana, prevaleceu o que o mesmo professor relata como concepção autotutelar do Direito do Trabalho, uma visão mais liberal, "que sustenta o retraimento do Estado para que os próprios interlocutores sociais estabeleçam diretamente entre si enlaces jurídicos e formas de composição dos seus conflitos, pressupondo, para o equilíbrio no eixo que une as duas pontas da questão, os empregadores e os trabalhadores, a tutela do mais fraco não através da intervenção do Estado, mas pela valorização dos direitos coletivos do trabalho que implica o reconhecimento da liberdade sindical, o desatrelamento dos sindicatos do Estado (...), a ampliação da negociação coletiva como forma ideal de autocomposição destinada a constituir normas jurídicas não estatais, mas criadas pelos próprios particulares $e$ reconhecidas pelo Estado, a arbitragem privada como forma substitutiva ou equivalente à solução jurisdicional dos conflitos trabalhistas e o direito de greve como necessário meio de pressäo com o qual devem contar os trabalhadores para que possam reivindicar, nas negociações coletivas, com algum grau de possibilidade de atendimento" 3

De fato, no Japão, a célula dos sindicatos encontra-se dentro das empresas. Existe a valorização da composição amigável dos litígios assim como a noção de "parceria social" ${ }^{4}$ ocorrendo algumas vezes que os diretores executivos das empresas são escolhidos dentre os que participaram ativamente dos sindicatos, fortalecendo a busca de um equilíbrio de interesses na gestão das empresas. O Estado seria, então, "o guardião dos interesses maiores da sociedade e das garantias mínimas inafastáveis pelo poder dispositivo das partes. 5 garantias estas

3. Nascimento, A. M., Op. cit., p. 85.

4. Expressão utilizada por Amauri Mascaro Nascirnento para designar a conjunção de esforços para "dotar a relação jurídica de equilíbrio, para compensar a vantagem econômica do empregador (...) principalmente com o desenvolvimento da negociação coletiva de sentido pragmático, e a integração do trabalhador na empresa, que se faz por mecanismos de iniciativa desta, como o greevance norte-americano, que é a institucionalização da autocomposição dentro da empresa, a participação do trabalhador nos lucros ou resultados da atividade empresarial incluindo o acionariado, e, como na Alemanha, a participação na gestão com a reserva de um determinado número de cargos de diretoria das sociedades anônimas para serem ocupados por representantes eleitos pelos trabalhadores, formas destinadas a fazer com que as deliberações sociais e até mesmo algumas decisões de ordem economica da vida da empresa que possam afetar os trabalhadores sejam também pelos mesmos discutidas com a empresa' (Op. cit., p. 86).

5. Nascimento, A. M. Op. cit., p. 86. 
que acabam por configurar aqueles direitos básicos do Estado intervencionista da concepção heterotutelar do Direito do Trabalho, fazendo com que cheguemos à conclusão de que estas concepções não são estanques, mas sobretudo interrelacionadas, como aliás deixa claro Amauri Nascimento.

O modelo do Direito do Trabalho japonês foi praticamente estruturado depois da II Guerra Mundial, com a ocupação do seu território pelas Forças Aliadas e a pressão para que houvesse uma regulamentação do trabalho e a inclusão de dispositivos constitucionais que garantissem os direitos e deveres dos trabalhadores.

Não que inexistissem leis trabalhistas no período anterior à guerra. Houve algumas, como a de 1911, para empresas com mais de quinze empregados, estabelecendo uma idade mínima para o trabalho de mulheres e crianças, fixando um teto para as jornadas de trabalho, a proibição do trabalho noturno, a fixação de feriados e dias de descanso e restringindo o trabalho em condições perigosas e insalubres.

O professor Kazuo Sugeno ${ }^{6}$ observa que as leis anteriores tinham por objetivo suprir as deficiências da legislação civil que era aplicada aos contratos de trabalho e regulamentar, ainda que de forma insuficiente, suas condições.

Podemos afirmar, contudo, que, apesar dos esforços para garantir condições mínimas de trabalho, principalmente depois da participação do Japão na criação da Organização Internacional do Trabalho (OIT), em 1919, os resultados ainda deixavam a desejar. As verdadeiras inovações e garantias efetivas em relação ao trabalho, entre outras, só se estruturaram com as reformas introduzidas pelas Forças Aliadas, incluindo a nova Constituição.

2. As garantias constitucionais do trabalho

A Constituição do Japão, promulgada em 1946, trouxe dois dispositivos que tratam dos direitos e deveres dos trabalhadores. São corolários de direitos fundamentais do homem e assim estão redigidos: 
Art. 27. Todos terão o direito e a obrigação de trabalhar.

Os padrões de salários, horários, repouso e outras condições de trabalho serão estabelecidos pela lei.

As crianças não serão exploradas.

Art. 28. O direito dos trabalhadores de organizar-se, de celebrar acordos e agir coletivamente é reconhecido.

$\mathrm{O}$ art. $27, \S 1^{\circ}$ prevendo o direito e a obrigação de trabalhar consubstancia a visão do governo de que todas as pessoas que têm seu sustento através do trabalho têm direito à uma colocação condizente com sua capacidade no mercado de trabalho. Algumas leis foram editadas e são exemplos dessa obrigação do governo: Lei da Estabilização do Emprego de $1947,{ }^{7}$ Lei de Incentivo ao Emprego de Pessoas Deficientes de $1960,{ }^{8}$ Lei relativa à Estabilização do Emprego de Pessoas Idosas de 1971. ${ }^{9}$

A obrigação de trabalhar presente neste parágrafo consistiria na obrigação negativa do Estado de manter desempregados que, apesar de suas habilidades profissionais, simplesmente não querem trabalhar. Daí a exigência de se provar o esforço na busca de um emprego, por exemplo a ida à Agência Pública de Emprego, ${ }^{10}$ para se ter direito ao seguro-desemprego.

Assim, o direito constitucional de trabalhar, na visão de Kazuo Sugeno, comporta o dever do Estado de intervir no mercado de trabalho no intuito de permitir que os trabalhadores tenham emprego, mas também a garantia de subsistência daqueles que não têm ou não tiveram oportunidade de tal emprego.

Várias são as leis que vieram regulamentar o $\$ 2^{\circ}$ do art. 27 , dentre elas podendo ser citadas a Lei de Normas Trabalhistas de $1947^{11}$ e a Lei do Salário Mínimo de 1959. ${ }^{12}$

7. "Shokugyô Koyô Antei Hô", Lei n. 141, de 1947.

8. "Shôgaisha no Koyô no Sokushin ni Kansuru Horitsu", Lei n. 123, de 1960.

9. "Kônenreisha tô no Koyô no Antei tô ni Kansuru Horitsu", Lei n. 68, de 1971.

10. Há cerca de 630 escritórios desta agência em todo o território japonês, in Guia para Trabalhadores Nikkeis, pp. 30-31.

1 1. "Rôdô Kijunhô", Lei n. 49, de 1947.

12. "Saitei Chingin Hô", Lei n. 137, de 1959. 
A Lei de Normas Trabalhistas, como o próprio art. $1^{\circ}$ assim dispõe, veio estabelecer condições mínimas de trabalho, que não podem ser reduzidas por acordo entre as partes. Pelo contrário, devem as partes tentar ampliá-las.

Entre outras disposições, está a jornada de quarenta horas semanais e oito horas diárias, no máximo, sendo permitidas horas extras, conforme haja um acordo por escrito entre o sindicato e o empregador ou o representante dos trabalhadores no caso de não haver sindicato na empresa. Também férias anuais remuneradas de dez dias no mínimo, aumentando-se um dia a cada ano trabalhado, até vinte dias no máximo, entre outras previsões. ${ }^{13}$

$\mathrm{O} \S 3^{\circ}$ do art. 27 dispõe sobre a não-exploração das crianças, numa tentativa de evitar este grave problema social. Em 1947 foi editada também a Lei do Bem-Estar das Crianças. ${ }^{14}$

$\mathrm{O}$ art. 28, consubstanciando direitos coletivos, foi praticamente copiado da Constituição de Weimar, de 1919. Dele decorrem os direitos de organização e, por conseguinte, a possibilidade de filiação a um sindicato, assim como a autonomia sindical.

Também presente é o reconhecimento da possibilidade de negociação coletiva, cujos acordos são vinculantes e substituem disposições contratuais que lhe sejam contrárias.

O "agir coletivamente" a que se refere o art. 28 compreende o direito de greve e outras medidas que possam vir a ser tomadas durante uma reivindicação. É certo que são atos isentos de responsabilidades civil e criminal, mas desde que não haja abusos ou uso de força, conforme jurisprudência da Suprema Corte. ${ }^{15}$

13. A reforma da Lei de Normas Trabalhistas, em 1988, introduziu a nova jornada de trabalho de quarenta horas semanais. Porém, a sua implementação ocorreu de forma gradativa, diminuindo-se duas horas durante três anos (até 1991), mais duas horas nos outros três anos (até 1994), quando então a segunda reforma da referida lei, em 1994, estabeleceu jornada máxima de quarenta horas semanais e férias de dez dias no mínimo. Vale a pena ressaltar que há exceções para algumas atividades profissionais relacionadas à agricultura, pecuária e o setor pesqueiro, assim como para micro ou pequenas empresas. In: Yamaguchi, Toshio. Rôdôhô Dokuhon, pp. 78 e ss.

14. "Jidô Fukushin Hô", Lei n. Iti4, de 1947.

15. Segundo o prof. Hiroshi Oda, em seu Japanese Law (p. 340), a Suprema Corte em julgado de 1958 estabeleceu que "a greve deve se limitar à recusa de trabalhar" (tradução livre) e que impedir o empregador de "realizar seu negócio através do uso da força, ameaça ou obstrução da administração de sua propriedade não é permitido" (tradução livre). 
Leis editadas com o intuito de regulamentar os direitos coletivos são: a Lei de Ajuste das Relações Trabalhistas, de $1946,{ }^{16}$ e a Lei dos Sindicatos Trabalhistas, de 1949. ${ }^{17}$

Apesar destes dispositivos constitucionais se destinarem aos trabalhadores em geral, algumas categorias sofrem, por leis esparsas, restrições no que dizem respeito aos direitos coletivos. São elas: dos policiais, bombeiros e membros da Força de Auto-Defesa, que não conhecem nenhum dos três direitos coletivos enumerados; a dos funcionários públicos exercendo cargos burocráticos, que não podem negociar ou agir coletivamente; e os funcionários dos correios e de empresas públicas, que não podem agir coletivamente.

Estas restrições, conforme aponta Hiroshi Oda, ${ }^{18}$ foram objeto de ações questionando sua constitucionalidade. A princípio, a Suprema Corte acolheu o argumento de que as limitações aos direitos coletivos feriam a Constituição, mas, em 1973, houve uma mudança dessa posição sob o fundamento de que "embora o art. 28 inclua todos os trabalhadores, alguns estão sujeitos a restrições impostas por causa do interesse público, desde que sejam razoáveis" (tradução livre).

O fato é que não há unanimidade nesta questão, alvo de críticas por parte de pesquisadores do assunto, que consideram que o Governo possui um poder discricionário exagerado neste ponto, além dos que advogam que essas restrições conflitam com os padrões internacionais referentes aos direitos coletivos.

3. Características do modelo trabalhista japonês

O sistema trabalhista no Japão tem características muito peculiares e muitos autores dizem que teria sido a base de sustentação do crescimento e desenvolvimento econômico do Japão no período pós-guerra.

Seus aspectos fundamentais, conforme observa o emérito professor da Universidade de Tóquio, Toshio Yamaguchi, ${ }^{19}$ seriam três: o sistema de contratação por longo tempo (long-term ou lifetime employment), o pagamento de salários de

16. "Rôdô Kankei Chôsei Hô", Lei n. 25, de 1946.

17. "Rôdô Kumiai Hô", Lei n. 174, de 1949.

18. Oda, Hiroshi. Japanese Law, p. 321.

19. Em palestra proferida na Faculdade de Direito da USP, em 18 de setembro de 1996. 
acordo com o tempo de serviço na empresa e a existência de sindicatos nas empresas.

\subsection{Sistema de contratação vitalício e política salarial}

Embora o art. 14 da Lei de Normas Trabalhistas preveja o prazo máximo de 1 (um) ano para o contrato de trabalho, renovável no silêncio das partes, esta é uma prática não observada no cotidiano, tendo em vista que o trabalhador permanece na empresa praticamente até a idade de sua aposentadoria, que ocorre entre os 55 e sessenta anos de idade. Daí o fato da despedida ou demissão do empregado ser algo raro. Isto devido ao fato de que numa crise, ao invés de despedir, o empresário tenta manter seu quadro de funcionários, diminuindo o tempo de serviço, remanejando empregados de setores etc.

O sistema de contratação por longo tempo surgiu como uma alternativa diante da escassez de mão-de-obra qualificada no período de expansão econômica a partir do final da década de 40 até meados da década de 60. Como havia uma disputa por essa mão-de-obra, surgiu a idéia de se contratar um recémformado, capacitá-lo ao longo do tempo, incutindo um sentimento de lealdade para com a empresa, no intuito de conservá-lo ali.

Desta forma, o recém-formado é recrutado, independentemente de sua especialização na universidade. Os critérios de seleção são mais pessoais que profissionais e ao longo do tempo ele é treinado a atuar nos mais diversos setores da empresa.

Os contratados num mesmo ano começam recebendo salários iguais, que são reajustados anualmente. Recebem também bonificações de acordo com o tempo de trabalho. O salário alcança, portanto, um patamar ideal quando as pessoas atingem uma idade média de 35 anos.

O custo para esse tipo de contratação se apresentava mais baixo na época do pós-guerra, apesar do investimento alto para a capacitação do funcionário. Isto porque o salário ainda não atingia valores consideráveis, devido ao fato de que a grande maioria ainda se encontrava em início de carreira.

Atualmente, porém, devido ao alto custo de investimentos e de salários, somente grandes empresas, com mais de trezentos empregados, ainda 
mantém esse sistema tradicional de contratação, correspondendo a cerca de $30 \%$ do total dos empregados no Japão. ${ }^{20}$

A redução desse sistema de contratação não decorre somente da questão econômica e do fato do custo ser menor ao se contratar um executivo no meio de sua carreira, em torno dos quarenta anos, mas também por outros fatores, sendo um deles a influência americana depois do término da II Guerra Mundial e a difusão de valores individualistas, da vontade dos trabalhadores de serem promovidos por mérito, por competência e não por tempo de serviço. Também pela vontade de se aplicar conhecimentos mais específicos aprendidos na universidade.

Por essas razões, Toshio Yamaguchi acha que a tendência é de desaparecimento deste sistema de contratação a longo prazo. Mas não é o que pensa Vicki Beyer, ${ }^{21}$ para quem haverá uma redução desse tipo de contratação de maneira a se formar uma elite de trabalhadores desse nível, não desaparecendo de vez, inclusive porque são estes os empregados preferidos para ocuparem cargos elevados na empresa.

Verificam-se grandes mudanças no panorama do mercado de trabalho nos últimos cinco anos. A falência e a reestruturação de várias empresas acarretou um remanejamento de trabalhadores. Há mais mobilidade de emprego do que anteriormente. Mas, apesar destes fatos, consideramos também que este sistema não desaparecerá de uma hora para outra, mas será modificado na medida em que surgirem novas contingências.

\subsection{Sindicatos nas empresas}

A existência dos sindicatos nas empresas é outra das características do modelo trabalhista japonês. Dentre as vantagens deste sistema estaria o fato de que quaisquer problemas poderiam ser resolvidos em negociações no âmbito da empresa, evitando que pessoas estranhas interferissem nas relações entre empregadores e empregados.

De outro lado, poderiam trazer o perigo de intervenção nos interesses do sindicato pela empresa, através da influência dos empregadores. Mas, para evitar essa ingerência, a participação dos empregadores ou de seus representantes é

20. In: Beyer, Vicki. "The effect of the labor practices on Japanese corporate governance"

21. Beyer, V. Idem. 
proibida (art. $2^{\circ}$ da Lei dos Sindicatos Trabalhistas) e também essa possibilidade é considerada uma prática trabalhista injusta, passível de sanções (art. $7^{\circ}$ da Lei dos Sindicatos Trabalhistas).

Podem filiar-se aos sindicatos os empregados contratados de forma permanente e são asseguradas algumas garantias, como estabilidade, àqueles que têm participação ativa nos sindicatos. Algumas vezes são estes, conforme mencionado acima, os que podem vir a serem escolhidos para ocupar cargos de diretoria, por causa de sua visão ampla dos problemas, e da idéia de que seriam eles os mais capazes para harmonizar os interesses de ambos os lados (empregados e empregadores), bem como para estimular a cooperação dentro da empresa de forma a manter a competitividade e os empregos. Ressaltamos, entretanto, que o trabalhador deixa de participar do sindicato, quando passa a ocupar cargos de confiança, como, por exemplo, chefias de seções.

$\mathrm{O}$ direito de associação nem sempre existiu. ${ }^{22}$ Com a aplicação, no início do século, dos princípios de Direito Civil aos contratos de trabalho, muitas vezes as reivindicações, através de greves, eram vistas como violação daqueles, ensejando multas e às vezes até sanções penais. Exemplo disso foi uma lei de 1900, a Lei de Segurança Pública e Polícia, ${ }^{23}$ que vigorou até 1925 e que previa a punição daqueles que organizassem greves e que induzissem os trabalhadores a se filiarem a um sindicato.

O movimento sindical ganhou um impulso depois do término da II Guerra Mundial e o encorajamento da organização de sindicatos pelas Forças Aliadas. Segundo constatação do professor Hiroshi Oda, em apenas vinte meses depois da guerra, 17 mil sindicatos foram formados. ${ }^{24-25}$

Porém, esse incentivo à organização dos sindicatos pelas Forças Aliadas foi refreado por volta de 1947, devido às influências ideológicas de caráter

22. Com a Revolução Russa, de 1917, o Governo japonês passou a encarar todo movimento sindical como atentatório à ordem pública, reprimindo-o.

23. "Chian Keisatsu Hô", de 1900.

24. Oda, H. Japanese Law, p. 318.

25. O país, devastado pela guerra, recebeu de volta cerca de 5 milhões de soldados e civis que se encontravam no exterior. Este fato acirrou a concorrência no mercado de trabalho antes da reestruturação da economia. Então, para a conquista de melhores condições salariais e de trabalho, a associação dos trabalhadores se fez necessária. 
social, contínuas greves e paralisações e também por causa da força que os sindicatos em geral adquiriram, especialmente o dos funcionários públicos.

Então, em 1948, foi aprovada a Lei das Relações Trabalhistas nas empresas públicas nacionais, ${ }^{26}$ restringindo a atividade sindical destes trabalhadores, não mais podendo estes interferir em questões concernentes ao setor privado. Essa separação do setor público e privado remanesce até os dias atuais, na medida em que existem leis próprias que regulamentam a atividade de algumas categorias, até mesmo restringindo suas ações coletivas, o que foi referido no item 2 acima.

\section{A evolução do Direito do Trabalho e o desenvolvimento econômico}

Pode-se identificar, em linhas gerais, quatro grandes fases do Direito do Trabalho, no Japão depois da II Guerra Mundial, relacionando-as ao período econômico vivenciado.

Assim, teríamos uma primeira fase (final da II Guerra Mundial até a década de 60) de legislação e recepção de valores ocidentais, notadamente americanos, conjugada com uma fase de reerguimento e crescimento econômico, na qual foram editadas várias leis, como a Lei de Ajuste das Relações Trabalhistas, de 1946, para estabelecer os procedimentos trabalhistas, a Lei de Normas Trabalhistas, de 1947, que veio regulamentar as condições de trabalho previstas na Constituição do Japão, assim como incorporar as referências internacionais sobre a matéria refletidas nas convenções da Organização Internacional do Trabalho (OIT). ${ }^{27}$

Ainda nessa fase, de reerguimento econômico, devido às altas taxas de desemprego, houve um desenvolvimento de mecanismos de assistência aos desempregados, podendo ser citadas as leis de 1947, relativas à Estabilização do Emprego $^{28}$ e a do Seguro-Desemprego. ${ }^{29}$

\section{6. "Kokuei Kigyô Rôdôkankei Hô", Lei n. 257, de 1948.}

27. O Japão participou da criação da OIT, em 1919, na qualidade de signatário do Tratado de Versalhes, como um dos países vencedores na I Grande Guerra. Ressaltamos este fato para não deixar a idéia de que as recomendações da OIT só foram incorporadas na legislação japonesa depois da II Guerra Mundial. O fato é que o sistema trabalhista japonês foi consolidado depois do término da guerra, mas a incipiente legislação do período anterior já mostrava um esforço do Japão em se adequar aos padrões internacionais em matéria trabalhista.

28. V. nota n. 7.

29. "Shitsugyô Hoken Hô", que foi substituída pela "Koyô Hoken Hô", Lei n. 116, de 1974. 
A segunda fase (final da década de 60 até a de 80 ) foi a da consolidação do sistema, algumas reformas e ajustes, devido ao declínio econômico provocado pela queda abrupta da produção com a crise do petróleo, de 1973, e o aumento do desemprego. Foram tomadas medidas para criação de empregos e de ajuste das pensões dos desempregados, favorecendo as pessoas idosas e as de meiaidade, dada a dificuldade maior que têm de recolocação no mercado de trabalho. Tudo numa tentativa de prevenir um colapso social.

$\mathrm{Na}$ terceira fase (década de 80 ), houve um aumento na produção devido ao crescimento dos mercados doméstico e internacional. Devido às inovações tecnológicas e ao crescimento do setor de serviços, houve uma reestruturação no mercado de trabalho.

Cresceu nesta fase a participação da mulher, o que, afora o fato do Japão ter assinado a Convenção da ONU sobre a Eliminação de Todas as Formas de Discriminação contra a Mulher (1979), fez com que se editasse, em 1985, a Lei sobre Oportunidades Iguais entre Homens e Mulheres em Matéria de Emprego, ${ }^{30}$ cujo intuito foi o de efetivar a igualdade entre homens e mulheres prevista na Constituição japonesa, além de reafirmar o disposto no art. $4^{\circ}$ da Lei de Normas Trabalhistas, que dispunha sobre a equiparação de salários entre homens e mulheres que ocupassem posições iguais de trabalho.

Entretanto, apesar destes dispositivos legais, o que se verifica, na realidade, é que os homens são mais privilegiados do que as mulheres nas promoções, o que acaba por resultar numa diferenciação de salário. Segundo estatísticas, somente $12,2 \%$ das empresas com mais de 5 mil empregados têm mulheres em cargos de chefia.

A necessidade de absorção da mão-de-obra feminina no Japão é premente na observação de alguns autores, principalmente tendo em vista que a perspectiva para o ano 2010 é de que pelo menos $20 \%$ da população já esteja em idade de aposentadoria. Diante deste fato, o Governo japonês está planejando postergar o início da aposentadoria de sessenta para 65 anos para os homens e de 55 para sessenta anos para as mulheres.

O que ocorre hoje, contudo, é que com a crise que assola o país, as grandes empresas começaram a remanejar os empregados que atingem a idade de cinqüenta anos, convidando-os a se demitirem voluntariamente, mediante 
oferecimento de vantagens adicionais. Caso o empregado insista em permanecer no emprego depois dos 55 anos, poderá fazê-lo, mas não haverá promoções, cargos de confiança, nem aumentos salariais.

Podemos sentir os efeitos da crise também no que concerne à contratação de funcionários recém-formados. Segundo notícias da imprensa, apenas $80 \%$ dos jovens que concluíram os cursos universitários e colegiais têm empregos garantidos, a partir do ano fiscal de 1999 , que se iniciou no dia $1^{\circ}$ de abril.

Diante destes fatos, identifica-se uma quarta fase (meados da década de 90), em que se observa uma mudança substantiva nos cenários das fases anteriores. Com o fim da chamada "economia de bolha" ${ }^{31}$ e das crises no mercado financeiro internacional, verifica-se a retração tanto nas demandas interna como internacional. Atualmente o Japão vive uma crise sem precedentes, refletida no índice nunca antes atingido de 4,3\% de pessoas desempregadas.

Esse índice de desemprego provoca, dentre outras coisas, uma disputa no mercado de trabalho, até mesmo por serviços braçais ou monofuncionais, antes desprezados pelos japoneses. Assim, os estrangeiros ${ }^{32}$ que exerciam estas funções estão sendo substituídos pelos próprios japoneses.

5. Solução de litígios trabalhistas

No Japão, diversamente do Brasil, não há órgãos jurisdicionais especializados em resolver questões trabalhistas. Estas são apreciadas por órgãos administrativos, as chamadas Comissões Trabalhistas, que existem em nível nacional (Comissão Trabalhista Central) e regional (nas províncias Comissões Trabalhistas Locais).

31. Trata-se do "boom" que entusiasmou a economia japonesa na segunda metade da década de 80. Houve grandes especulações no mercado imobiliário, mobiliário e também investimentos em objetos de arte. Os bancos financiavam os investidores em troca de garantias. Sobreveio a crise, quando se verificou a desvalorização destes ativos, o que acarretou uma grande crise financeira, resultando em falências e fusões de instituições financeiras.

32. Cerca de $250 \mathrm{mil}$ pessoas de nacionalidade brasileira residem no Japão atualmente, constituindo essa população o terceiro maior contingente de estrangeiros daquele país. Segundo a imprensa, há um grande número de desempregados também entre os brasileiros, que pode variar entre 5 a 10 mil pessoas. 
Essas comissões são formadas por representantes dos empregadores, dos empregados e daqueles que defendem o interesse público, ${ }^{33}$ em igual número. Têm competência para analisar e resolver os casos de práticas trabalhistas injustas e também litígios, tanto coletivos, quanto individuais.

Empregador e empregado podem resolver suas demandas, conforme as regras estabelecidas dentro da empresa, negociadas e aprovadas pelas Comissões Trabalhistas. Se não chegarem a um acordo, podem levar a questão à Comissão Trabalhista respectiva, instaurando-se procedimentos de mediação, conciliação e arbitragem, nesta ordem.

Esta hierarquia entre os procedimentos decorre por certo da própria natureza destes institutos de solução alternativa de litígios. O mediador é alguém que ouve as partes, ajuda a esclarecer a situação, mas não faz propostas, deixando que as partes promovam seu próprio acordo.

Já o conciliador é uma pessoa que não só ouve as partes, mas dá uma proposta de solução, dentro daquilo que seria mais razoável na situação. As partes podem ou-não aceitar, mas o fato é que o conciliador participa mais ativamente no processo de tentativa de resolver a questão controvertida.

$\mathrm{E}$ o árbitro ouve também os argumentos de ambos os lados, porém, não-só ele propõe, mas decide o litígio levado ao seu conhecimento, como um juiz, cuja decisão vincula as partes.

Se a solução que foi dada a um determinado caso não foi satisfatória, existe a possibilidade de recurso à Comissão Trabalhista Central para revisão da decisão. Se ainda assim a parte não se contentou com a revisão, pode-se recorrer ao Judiciário, o que é extremamente raro.

\section{Conclusões}

Longe de desvendar todas as minúcias do modelo trabalhista adotado pelo Japão, pretendeu-se oferecer uma visão macroscópica do Direito do Trabalho japonês, certamente um ponto de partida para reflexões acerca da influência deste sobre a economia do país e vice-versa, sobre ser o modelo trabalhista japonês uma das bases de sustentação da posição econômica do Japão, no mundo.

33. Nesta categoria, verifica-se a presença de um grande número de professores universitários da área social ou especializados em Direito do Trabalho. 
Nota-se a influência americana sobre vários aspectos, acentuadamente depois do término da II Guerra Mundial e da promulgação da Constituição democrática, em 1946, que se faz sentir na sociedade em geral e, por conseguinte, no Direito também.

É preciso, no entanto, permear o olhar sobre o Direito japonês com uma certa cautela, tendo em vista que apesar de poder ser incluído entre os sistemas de Direito pertencentes à família romano-germânica, no qual encontra-se o Brasil, possui o Direito japonês algumas singularidades, motivo pelo qual foi analisado pelo comparatista francês René David, em capítulo próprio, destinado aos "direitos do extremo oriente" 34

Isto porque embora o Japão tenha recepcionado o Direito ocidental, processo que teve início na Restauração Meiji, em 1868, há uma convivência de valores culturais tradicionais com concepções ocidentais completamente díspares, o que acaba por causar uma sensação de existência de várias contradições.

O motivo disso seria o fato de que essa recepção do Direito ocidental não foi acompanhada da mudança dos hábitos, costumes e do "modo de ser" japonês. Modificou o tratamento de algumas questões no Japão. Entretanto, é interessante observar esse processo de adaptação, na realidade, de importação de conceitos ocidentais, porque se aparentemente o japonês se ocidentalizou, não o fez com sua alma, com seu espírito.

Por causa do confucionismo, do budismo e do xintoísmo, que trazem consigo a idéia da imutabilidade das regras que comandam a natureza, bem como a necessidade de aceitar as coisas tal como elas são, existe uma preocupação acentuada com a harmonia, a estabilidade das relações sociais e assim a manutenção da coesão social. Reflete isso uma concepção organicista da sociedade, na qual o homem é apenas um membro, uma parte de um todo, diversamente da concepção contratualista, onde existe uma reunião de indivíduos que formam o Estado.

Dentro dessa perspectiva, o indivíduo é menos sujeito de direitos que de deveres. Ele é apenas mais um que deve contribuir para a coletividade. Daí uma certa dificuldade de apreensão dos chamados direitos individuais.

Essa noção do todo, do coletivo, fez com que os trabalhadores, por exemplo, vissem na empresa uma extensão de sua familia, sendo eles apenas uma parte das engrenagens que fazem todo o sistema funcionar. Daí o espírito de lealdade

34. David, René. Os Grandes Sistemas de Direito Contemporâneo. 
do empregado em relação à empresa ${ }^{35}$ e também as medidas alternativas do empresário para manutenção dos empregos, mesmo que isso signifique ver seus dividendos diminuídos.

Além disto, outra peculiaridade importante apontada, entre outros, pelo professor Yosiyuki Noda ${ }^{36}$ é o fato de que as relações humanas são governadas por regras de conduta não-escritas, denominadas on e giri, que correspondem ao dever de se conduzir de uma maneira adequada e harmônica em relação a uma terceira pessoa. A hierarquia adquire muita importância, na medida em que os deveres que uma pessoa tem para com outra diferem conforme se encontrem em posições sociais diferentes: pais e filhos, mais velhos e mais novos, marido e mulher, empregador e empregado, etc.

Dessas regras de comportamento, afere-se o reduzido espírito de litigiosidade do japonês, no sentido de ser pouco afeito a resolver seus problemas no Judiciário. Daí a ênfase em meios alternativos de solução de litígios, tais como previstos na legislação trabalhista, do uso da mediação, da conciliação e da arbitragem, evitando-se o processo judicial que, em última análise, significaria a incapacidade de manter a harmonia e a compreensão mútuas nas relações sociais.

É certo, porém, que todas essas peculiaridades japonesas estão presentes de uma maneira bem mais atenuada hoje em dia, ${ }^{37}$ mas não se pode deixar de tê-las em mente, porque somente assim, revendo alguns aspectos históricoculturais, poder-se-á compreender melhor a essência do Direito japonês.

São Paulo, maio de 1999.

35. Há quem diga que essa lealdade seria um resquício do feudalismo, onde a obediência dos súditos aos senhores feudais e destes para com o Shôgun era levada às últimas consequiências. Com o advento da Era Meiji, o Estado, na figura do Imperador, tornou-se a autoridade máxima em função de quem os súditos deviam obediência. Com a democratização no período pós-guerra, a fidelidade do empregado em relação à empresa veio substituir a do súdito em relação ao Estado.

36. Noda, Yosiyuki. Introduction au droit japonais.

37. Uma grande mudança de valores pode ser observada nos últimos anos. A geração do pósguerra está abandonando rapidamente os valores tradicionais como fruto de uma educação que aos poucos perdeu a conotação de obediência rígida, dando maior ênfase ao individualismo. Uma evidência concreta deste fato e que mostra que todas essas peculiaridades estão bem mais suavizadas atualmente é o fato de que o número de processos existentes no Japão mais do que dobrou desde os anos 50 . 
7. Bibliografia.

BECKER, Vicki. "The effect of labor practices on Japanese Corporate Governance" Artigo em circulação na Internet.

DAVID, René. Os Grandes Sistemas de Direito Contemporâneo. $3^{\mathrm{a}}$ ed., São Paulo, Martins Fontes, 1996.

NASCIMENTO, Amauri Mascaro. Curso de Direito do Trabalho. $10^{\mathrm{a}}$ ed., São Paulo, Saraiva, 1992.

NODA, Yosiyuki. Introduction au Droit japonais. Paris, Librairie Dalloz, 1966.

ODA, Hiroshi. Japanese Law. Londres, Butterworths, 1992.

SUGENO, Kazuo. Japanese Labor Law. Tokyo, University of Tokyo Press, 1992.

YAMAGUCHI, Toshio. O Direito do Trabalho no Japão. Palestra proferida na Sala da Congregação da Faculdade de Direito da USP em 18 de setembro de 1996.

Rôdôhô Dokuhon. $3^{\mathrm{a}}$ ed., Tokyo, Yuhikaku, Hagisawa, Kiyohiko \& Yamaguchi Toshio Editores, 1994.

Guia para Trabalhadores Nikkeis, edição bilíngüe, Centro de Estabilização do Emprego nas Indústrias, Tokyo, 1997. 